\title{
Study of CR-39 SSNDs irradiated with different types of radiation by FTIR spectroscopy and $\alpha$-range determination
}

\author{
Kh. M. Abdel Raouf* \\ Umm Alqura University, KSA.and Zagazig University hospitals, Egypt
}

Email address:

khaledraoof@gmail.com

To cite this article:

Kh. M. Abdel Raouf. Study of CR-39 SSNDs Irradiated with Different Types of Radiation by FTIR Spectroscopy and $\alpha$-Range Determination, American Journal of Environmental Protection. Vol. 2, No. 2, 2013, pp. 53-57. doi: 10.11648/j.ajep.20130202.14

\begin{abstract}
Studies of CR-39 irradiated with $\gamma$-rays, X-rays and alpha particles by FTIR spectroscopy are presented. In this work we make a comparison between the effect of many types of radiation on the sensitivity of CR-39 detector by using the FTIR spectrometer. It was found that,investigated CR-39 is so sensitive for all types of radiation used that was used as a dosimeter for these types of radiation. The determination of alpha particles range in CR-39 plastic recorder is an important parameter in the field of charged particle identification using Solid State Nuclear Track Detectors. In this work the optical denisty of the detector was calculated and then it is used to determine $\alpha$-range. An over- etched track profile method and a theoretical method derived by Almasi are compared. A good agreement between the three methods used in $\alpha$-range determination was found.
\end{abstract}

Keywords: CR-39, FTIR- Spectroscopy

\section{Introduction}

Characteristics of solid state nuclear track detectors were studied by many authers. It is well known that, track size, bulk etch rate and track etch rate are affected by exposing detectors to several types of radiations such as, $\mathrm{X}$-ray, $\gamma$-rays, UV and alpha particles $[1,2,3,4,5,6]$. The two main changes noticed in polymers are [7] :

1) Chain cross linking resulting in an increases of molecular weight because of a large number of free radicals produced in polymer.

2) Chain scission resulting in a decrease of molecular weight and substantislly changing in polymer material properties.

In addition to these changes, small molecules such as $\mathrm{Co}$, $\mathrm{Co} 2$ and $\mathrm{H} 2$ may be produced resulting from bond scission.

In this study FTIR spectroscopy technique was used to analyze the effect of radiation on CR-39 plastic detector which is used in several studies. $(9,11,13,14)$

FTIR-spectrometers analyze light by measuring the fourier transformed intensity of a spectrum with the use of a Michelson interferometer or modified versions of it. The interferogram is obtained by a scanning mirror and the spectrum obtained by a Fourier Transformation .
The main advantage of this technique arises from the fact that the photo detector receives light from all spectral elements simultaneously at each position of the scan . However the fourier transform technique is sensitive to changes in the spectrum during one scan because these changes are interpreted as a contribution to the complete wavelength range.

Depending on the fact that the shape of a single track is changing continuously during the etching process, we study the relation between optical density and differnent values of alpha particles energy and concentrations of etchant solution. The range of $\alpha$-particles in CR-39 was studied by many authers this work is to make a comparison between three methods which are used in $\alpha$-range determination.

\section{Experimental Procedure}

Three group of samples were exposed to alpha particle energies 1, 2, 3, 4 and $5 \mathrm{MeV}$ respectively and then etched in $6 \mathrm{~N} \mathrm{NaOH}$ at $(70+1) \mathrm{Co}$ for etching time $11 \mathrm{hrs}$. Specimens of CR-39 are also irradiated with 500, 1000, 1500 and 2000 rad of gamma rays from ALCYON-II Co60 teletherapy machine in the Oncology unit of Zagazig 
University Hospitals. The samples of CR-39 irradiated by alpha particles of energies 2, 3, 4 and $5 \mathrm{MeV}$ etched at $6 \mathrm{~N}$ $\mathrm{NaoH}$ at $(70+1)$ oC for etching time $30 \mathrm{hrs}$.

Specimens of CR-39 are irradiated with 2 Gy of gamma rays from ALCYON-II Co-60 teletherapy machine in the Oncology unit of Zagazig University Hospitals, also CR39 recorders are irradiated with X-rays of 85 kilo volt and 200 m.A from X-ray tube DS-TA-5A Toshiba and finally CR-39 detectors are irradiated with $\alpha$-particles of energy 4 $\mathrm{MeV}$ from Am-241, thin source of active diameter $5 \mathrm{~mm}$ and activity $3.7 \times 108 \mathrm{~Bq}$. The source was covered by 100 $\mathrm{Mg} / \mathrm{cm} 2$ thin layer gold. Mattson (Unicam) Fourie Transform Infrared (FTIR) spectrometer is used for measuring and scanning the infrared absorption spectra at a resolution of $4 \mathrm{~cm}^{-1}$.

\subsection{Methods of A-Range Determination}

1- By using optical density O.D. of CR-39 irradiated by $\alpha$-particles is measured by using formula[15] :

$$
\text { O.D. }=\log \frac{100}{V}
$$

where $\mathrm{V}$ is the reading of millivoltmeter in presence of the sample.

which was plotted versus etching time (te) to obtain the time (tpeak) which is the time assumed to remove a layer equal to the range of $\alpha$-particles in the detector and by which we can calculate the range as following :

$$
\mathrm{R}=\mathrm{V}_{\mathrm{B}} \mathrm{t}_{\text {peak }}
$$

where $V_{B}$ is bulk etch rate .

$$
\mathrm{V}_{\mathrm{B}}=\frac{\Delta m}{2 \rho \cdot A \cdot t}
$$

Where $\Delta m$ is the mass decrement, $\rho$ is the detection density, A is area of the surface of detector and $t$ is etching time.

2- By using the overetched track profile technique: $\alpha$ range determination had been measured at various energies using this method [16].

For $t_{e} \gg t_{R}$, where $\left(t_{e}\right)$ is the etching time and $\left(t_{R}\right)$ the etching time assumed to remove a thickness equal to range R. It is found that the diameter square $\left(\mathrm{d}^{2}\right)$ exhibits linearity with etching time $\left(t_{\mathrm{e}}\right)$. The range is calculated by using formula:

$$
R=\frac{S}{16 V_{B}}-\frac{I}{S} V_{B}
$$

where $\mathrm{S}$ is the slope of straight line of $\mathrm{d}^{2}$ and $\mathrm{t}_{\mathrm{e}}$ relation and $\mathrm{I}$ is the intercept of straight line with $\mathrm{x}$-axis .

3- Using the Almasi et al theoretical tables [17]:

In this model, Almasi calculated the range of $\alpha$-particle theoretically in tables depending on the value of

$$
\frac{\text { Energy }}{\text { Atomic mass unit of particle }} \text { i.e } \frac{\mathrm{MeV}}{\mathrm{AMU}}
$$

\section{Results and Discussion}

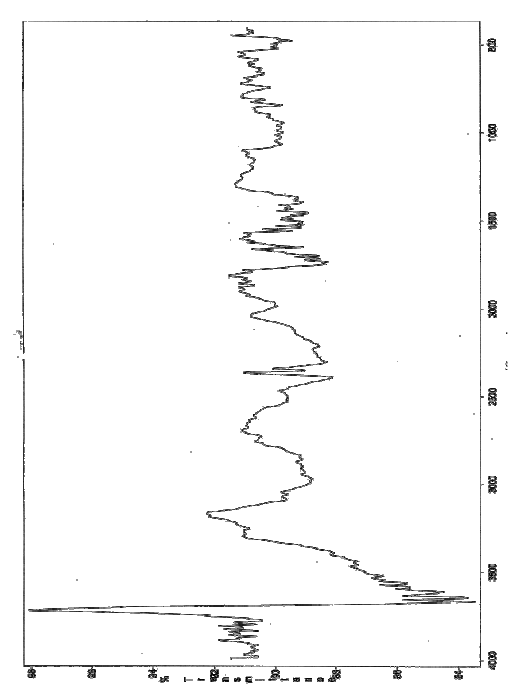

Fig (1) IR spectrum of unirradiated CR-39

Figure (1) shows, IR spectrum of unirradiated CR-39 specimen of thickness $500 \mu \mathrm{m}$ one notice that, there are four characteristic bands for IR spectroscopy of CR39, these bands are : $\mathrm{OH}$ group characterized is stretching band at wavenumber about $3600 \mathrm{~cm}^{-1}$.the second band is carbobnyl group $\mathrm{C}=\mathrm{O}$ is characterized at wavenumber $1725 \mathrm{~cm}^{-1}$. The last band is $\mathrm{C}-\mathrm{H}$ stretching band at wavenumber $3000 \mathrm{~cm}^{-1}$.

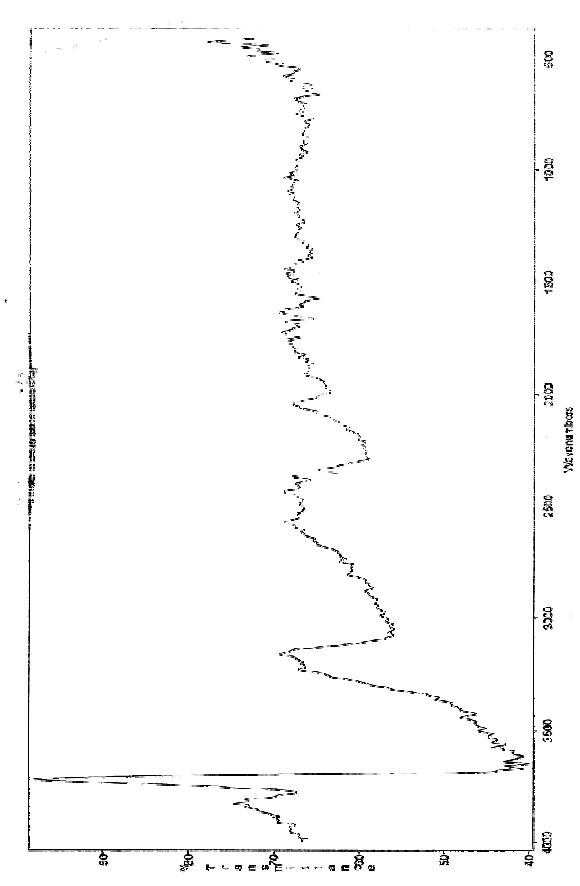

Fig (2) IR-Spectrum of CR-39 irradiated with 2000 rad of $\gamma$-rays 
Figure (2) shows the unirradiated CR-39 and that is irradiated with $2000 \mathrm{rad}$ of $\gamma$-rays .One observed the disappearance of three characteristic bands, C-O group, $\mathrm{C}=\mathrm{O}$ group and $\mathrm{C}-\mathrm{H}$ stretching band. For irradiated samples two bands of $\mathrm{Co} 2$ are formed, this occur because of the cross linking of the $\mathrm{C}-\mathrm{O}$ and $\mathrm{C}=\mathrm{O}$ groups which leads to the recombination of $\mathrm{O}$ with $\mathrm{CO}$ molecule, at wavenumbers $2300 \mathrm{~cm}^{-1}$ and $660 \mathrm{~cm}^{-1}$ respectively and the $\mathrm{O}-\mathrm{H}$ group is steal noticed at $3600 \mathrm{~cm}^{-1}$.

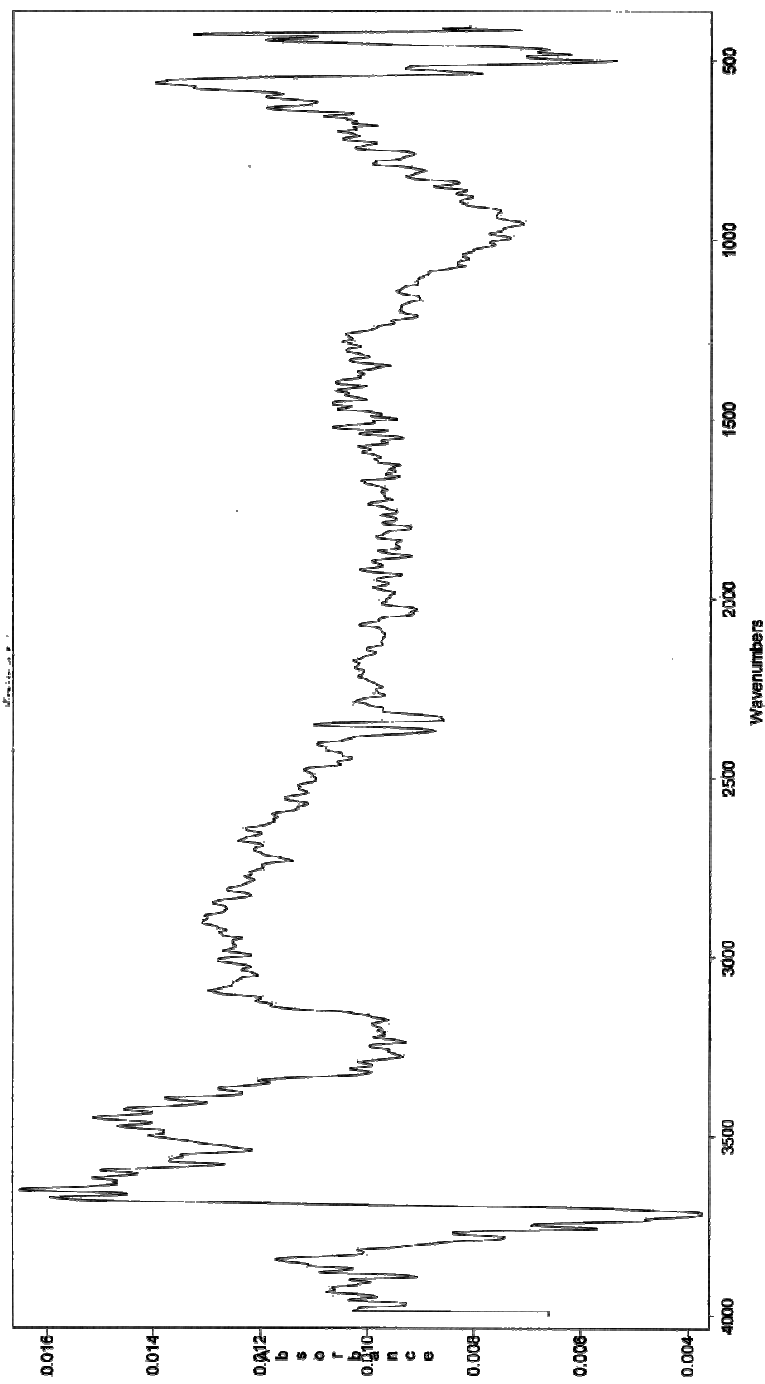

Fig (3) IR-Spectrum of CR-39 irradiated by $85 \mathrm{kv}$ and $200 \mathrm{~mA}$ X-ray from $X$-ray tube

Figure (3) shows the IR-spectrum of CR-39 irradiated with X-rays, is $85 \mathrm{k}$.volt and $200 \mathrm{~m}$.A. from X-ray tube model DS-TA-5A Toshiba. It is clear that, the C-H stretching band is shifted to a wavenumber $3000 \mathrm{~cm}^{-1}$ and a deformation band at $2400 \mathrm{~cm}^{-1}$.

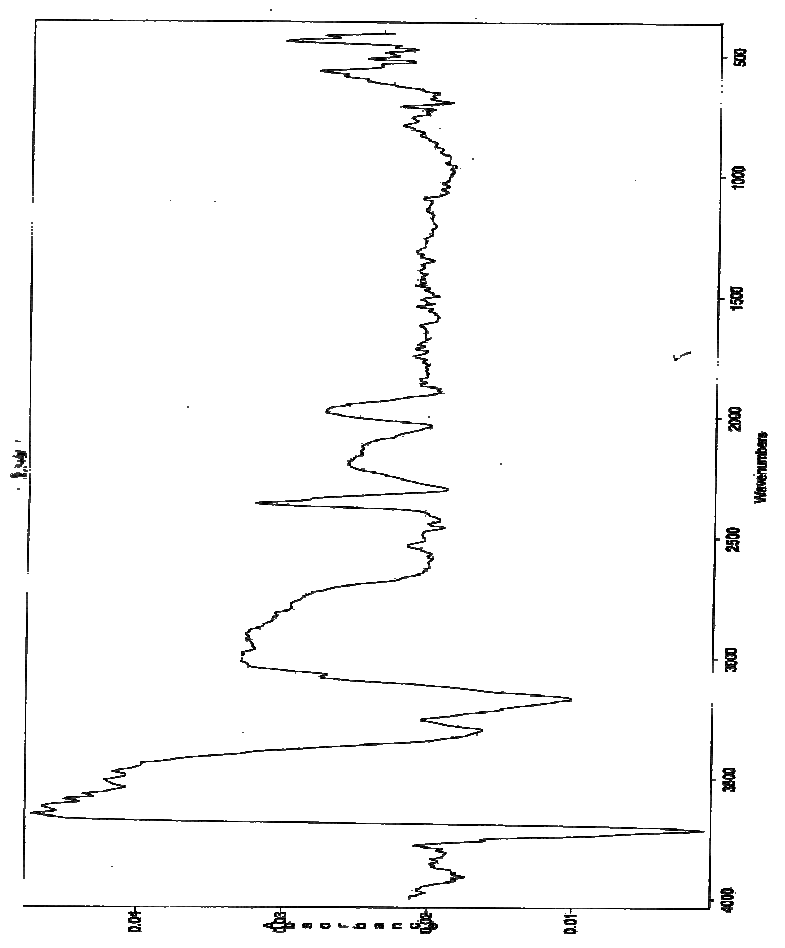

Fig (4) IR Spectrum of CR-39 irradiated by $4 \mathrm{MeV} \alpha$-particles from Am241 thin source

IR-spectrum of CR-39 detector irradiated by $4 \mathrm{MeV}$ of $\alpha$-particles is shown in figure (4). Two medium bands of $\mathrm{C}-\mathrm{H}$ group at absorption wavenumbers 3200 and $3400 \mathrm{~cm}^{-1}$ were noticed .Also two bands of $\mathrm{Co} 2$ are characterized at 2430 and $666 \mathrm{~cm}^{-1}$ was observed.

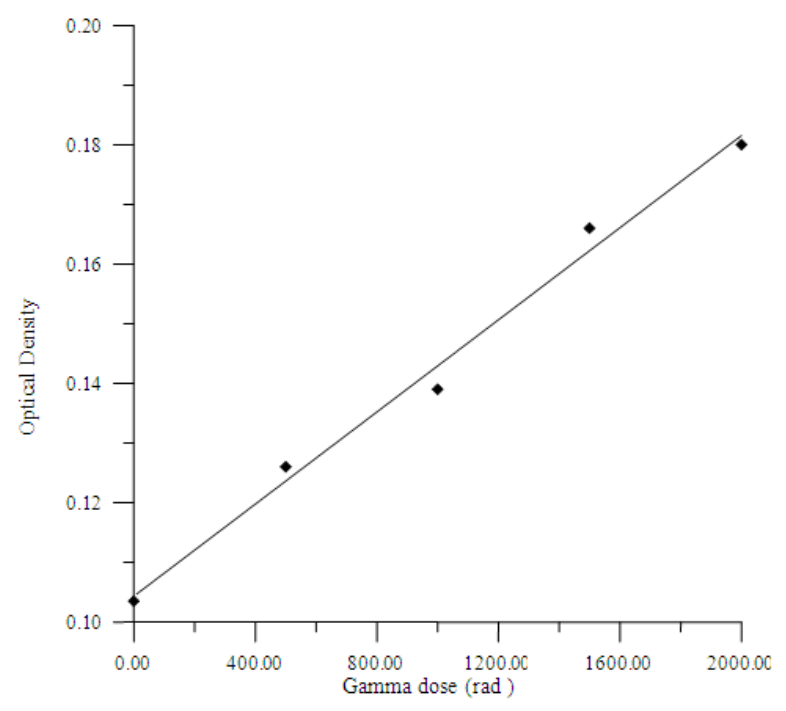

Figure (5) The variation of optical density with the exposure dose of $\gamma$ rays

Figure (5) shows the variation of optical density with the exposure $\gamma$-rays dose. It is clear that O. D. increases with $\gamma$-rays dose and this can be attributed by the increasing of damage caused by different doses of $\gamma$-rays on CR-39 


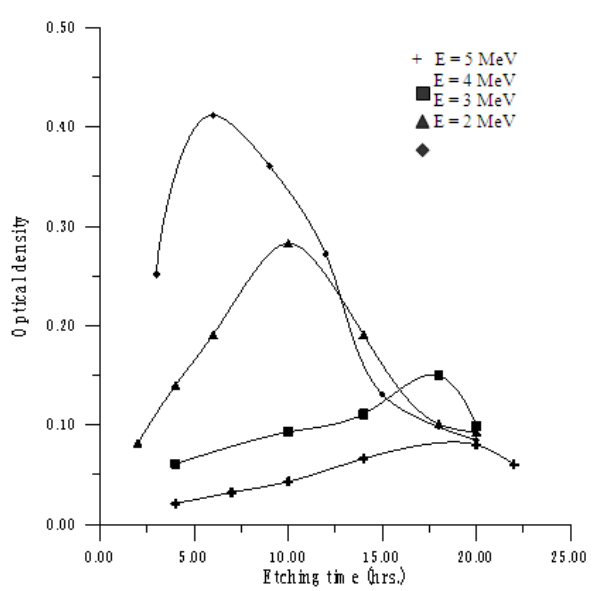

Figure (6) Variation of optical density with etching time for different values of alpha energy

Figure (6) shows the variation of optical density with the etching time for different energies of alpha particles. It is clear that O.D. increases linearly with increasing the etching time $\left(\mathrm{t}_{\mathrm{e}}\right)$ until a certain value of time $\left(\mathrm{t}_{\text {peak }}\right)$ and then it decreased. This decreasing may be explained by track overlapping, noticed. The range of alpha particles was calculated by the product of $\left(t_{\text {peak }}\right)$ and $V_{B}$.

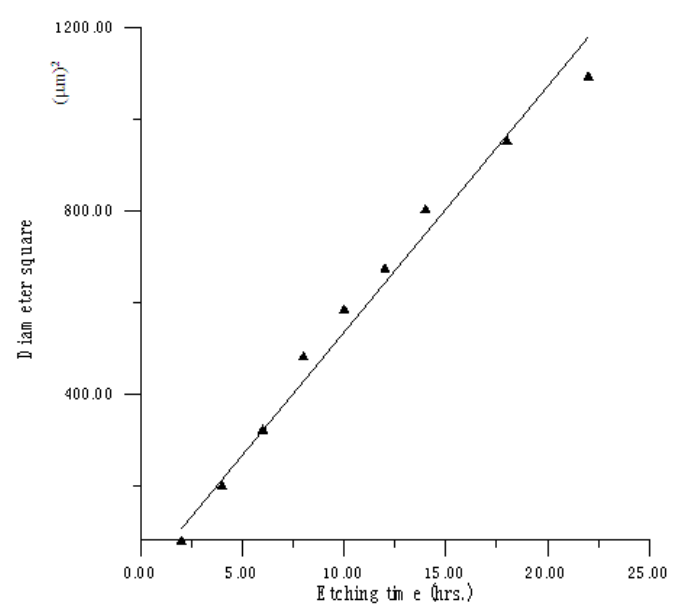

Figure (7) Diameter square (d2) as s function of etching time (te) for alpha energy $E \alpha=1 \mathrm{MeV}$.

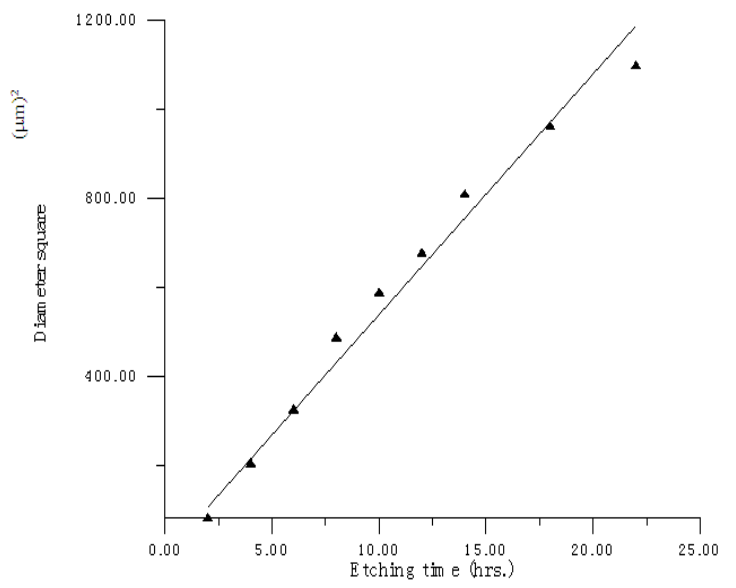

Figure (8) Diameter square $\left(d^{2}\right)$ as s function of etching time (te) for alpha energy $E \alpha=2 \mathrm{MeV}$.

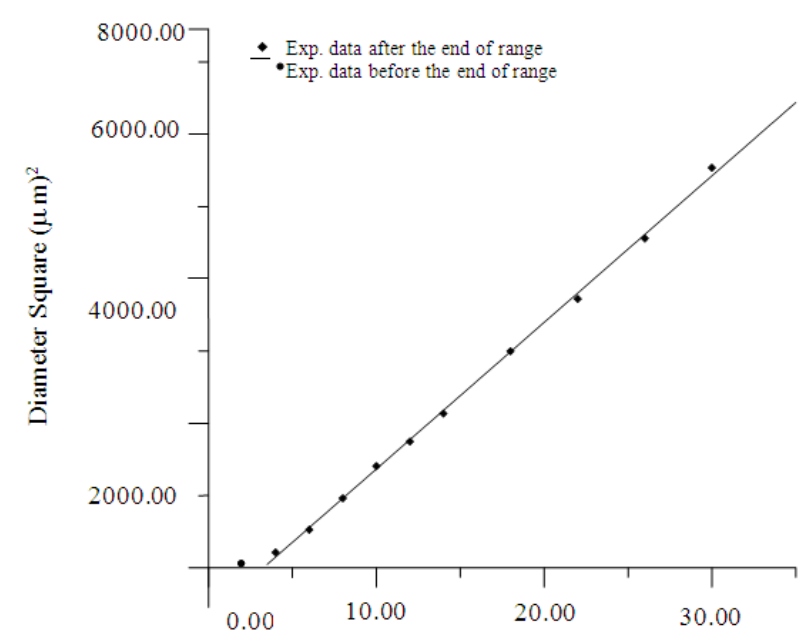

Eching time (hrs)

Figure (9) Diameter square $\left(d^{2}\right)$ as $s$ function of etching time (te) for alpha energy $E \alpha=3 \mathrm{MeV}$.

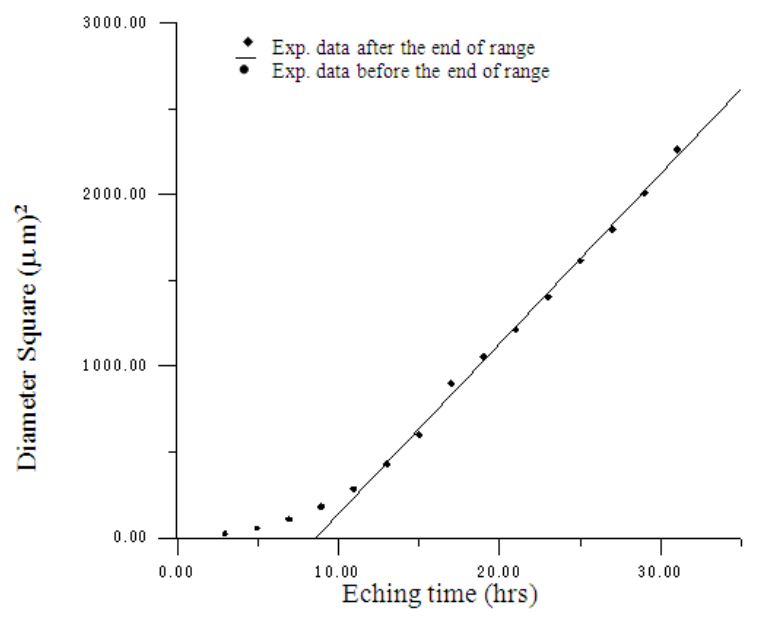

Figure (10) Diameter square $\left(d^{2}\right)$ as s function of etching time $\left(t_{e}\right)$ for alpha energy $E_{\alpha}=4 \mathrm{MeV}$.

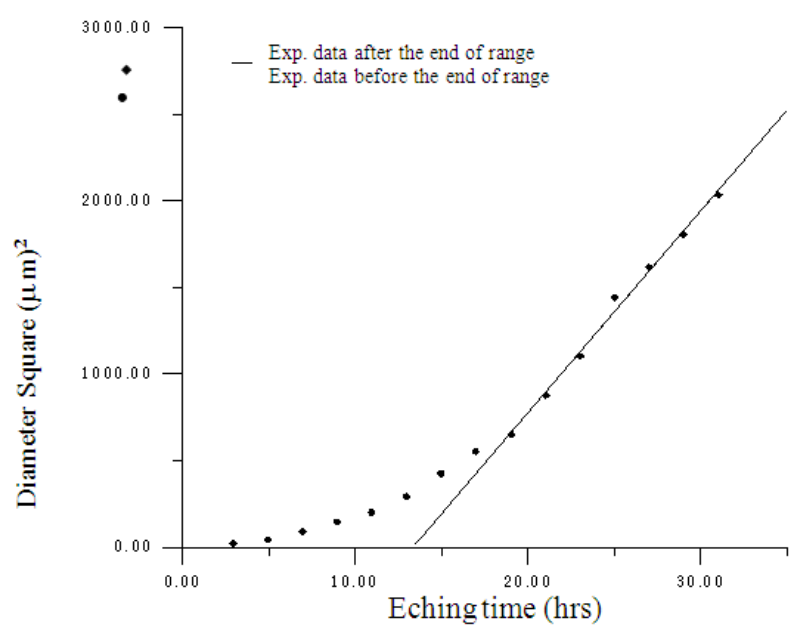

Figure (11) Diameter square $\left(d^{2}\right)$ as s function of etching time ( $\left.t_{e}\right)$ for alpha energy $E_{\alpha}=5 \mathrm{MeV}$. 


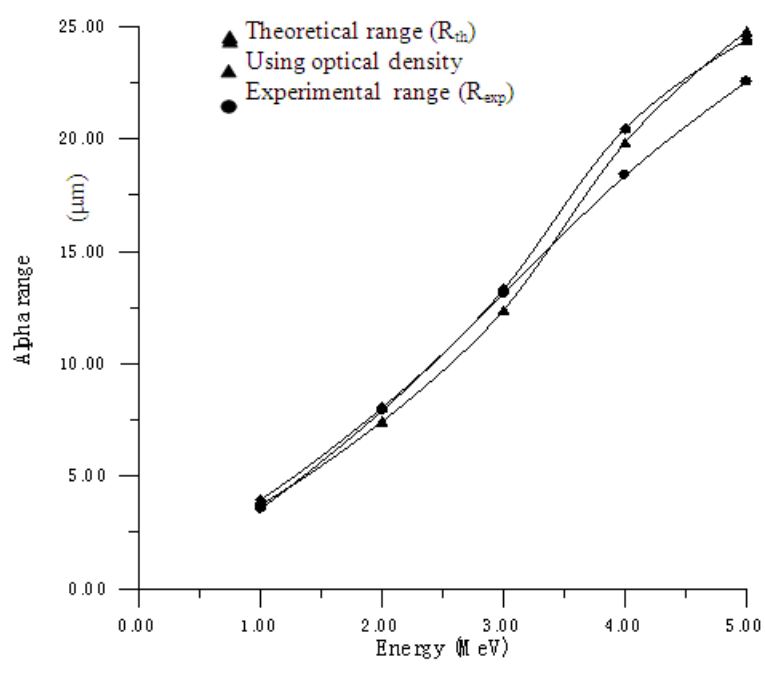

Fig (12) Comparison between the values of alpha range

The diameter square $\left(\mathrm{d}^{2}\right)$ then plotted versus etching time $\left(t_{\mathrm{e}}\right)$ see figures $(7,8,9,10$, and 11$)$. We then measured the slope of the linear part and the intercept with the x-axis, and then we can calculate the range of alpha particles from eqn (4).

Table 1 shows the comparison between the range values by using the three methods. It is clear that there is a good agreement between the three methods as shown also in figure (12).

\section{Conclusion}

FTIR spectroscopy of CR-39 detectors indicate that these detectors are very sensitive to different types of radiation and so this type of detectors can be used as a radiation dosimeter successfully. By using a simple experimental setup, optical density of CR-39 irradiated by $\alpha$-particles of different energies is measured and used in the determination of $\alpha$-range in CR-39. A comparison between this method which is used in this work and two other methods was studied, a agreement between the three methods was observed.

Table (1) : Comparison of different values of $\alpha$-particle range

\begin{tabular}{cccc}
\hline $\mathrm{E}$ & $\mathrm{R}_{\mathrm{th}}(\mu \mathrm{m})$ & $\mathrm{R}_{\exp }(\mu \mathrm{m})$ & $\mathrm{t}_{\text {peak }} \mathrm{V}_{\mathrm{B}}(\mu \mathrm{m})$ \\
\hline 1 & 3.948 & $3.55 \pm 0.21$ & $3.72 \pm 0.16$ \\
2 & 8.052 & $7.9181 \pm 0.15$ & $7.44 \pm 0.171$ \\
3 & 13.311 & $13.105 \pm 0.15$ & $12.4 \pm 0.203$ \\
4 & 20.47 & $18.37 \pm 0.2$ & $19.84 \pm 0.18$ \\
5 & 24.42 & $22.55 \pm 0.18$ & $24.8 \pm 0.22$ \\
\hline
\end{tabular}

\section{References}

[1] C. S. Chong uni L. F. Tan, Nucl. Tracks Tadient. Meas, 22, 101-104, (1993).

[2] M. Varnagy, J. Csokai and S. Szegedi, Nucl. Inst. and Meth. 119, 261-267, (1974).

[3] S. Charalambous, M. Zamani, Int. J. A 1. Ruduat. Isot., 36, $525-529,(1985)$

[4] M. M. Radwan, Rad. Meas., vol. 33, . 183-188, (2001).

[5] Sangeeta Prasher and Surinder sigh, Rad. Meas., vol. 36, Issue 1-6, . 105-105, (2003).

[6] R. Schweikani, S, A. Durrani, T. Tsurata, Nucl. Iracks Rudiat. Meas., 22, 153-156, (1993).

[7] C. S. Chaong, I. Ishak, R. H. Mahata and Y. M. Amin, Radiat. Meas., 28, 119-122, (1997).

[8] Barillon, R., M. Fromm, A. Chambaudet, R. Katz, J. P. Stoquert, and A. Pape, (1999). Bond scission cross sections for $\alpha$-particles in Cellulose Nitrate (CN). Radiat. Meas., 31, $71-75$.

[9] Chong C. S., I. Ishak, R. H. Mahat, and Y. M. Amin, (1997). UV-Vis and FTIR spectral studies of CR-39 plastics irradiated with X-rays. Radiat. Meas., 28, 119-122.

[10] Chong, C. S., M. A. C. Chan and L. F. Tan, (1993). The effect of X-ray irradiation on track formation in LR-115 Type II(1999). SSNTD application in science and technology Radiat. Meas., 31, 25-45.

[11] Gagnadre C., J. L. Decossas and J. C. Vareille, (1993). IR Spectroscopy studies of Poly carbonate irradiated by $\mathrm{H}^{+}$ and $\mathrm{Li}^{+}$ions. Nucl. Inst. And Meth, 73, 48-52.

[12] Khan, H. A., I. E. Qureshi, (1999). SSNTD application in science and technology Radiat. Meas., 31, 25-45.

[13] Meyers R. A., (2003). Encyclopedia of Analatical chemistry, Rantech Ltd, Trazana, C. A. USA.,.

[14] Saad A. F., S. T. Atwa, N. Yasuda, and M. Fujii, (2001). FTIR spectroscopy of carbon dioxide in CR-39 and SR-90 track detectors irradiated with ions and gamma rays at different energies and fluencies. Radiat. Meas., 34, 51-54.

[15] M. El-Hofy., H. El-Samman., W. Arafa., Determination of the range of alpha particles in SSNTD by optical density method, Rad. Meas., vol. 31, 241-244, (1999). El-Rahmany, $\mathrm{Ph}$. D. Thesis, unpublished, Nounfia university, (1993).

[16] Gy Almasi, and Somogyi, G., Atomki Kozlemenyek, vol. 23, 99-112, (1981).

[17] I Lic, R. and Najzer, M., Image formation in trock-etch detector, Nucl. Tracks Radiat Meas., vol. 17, 453-460 (1990). 